\title{
Bioequivalence and Bioavailability
}

\section{Edward T Maggio*}

Aegis Therapeutics LLC, 11770 Bernardo Plaza Ct., Suite 353, San Diego, CA 92128, United States

Pharmacology and pharmaceutics are integral parts of many allied branches of medical sciences. The development of novel drugs is already known to be a multistep process, one of the most crucial steps of which is checking the bioequivalence and bioavailability of the pharmaceutical formulation prepared. Development and standardization of methods of study of these factors can help in the identification of cost efficient alternatives of the adept methods of treatment, which in turn may help in the increased accessibility of treatment regimens. Hence, researchers across the world are busy experimenting with already standardized and novel pharmaceutical formulations, especially testing their bioequivalence and bioavailability.

The Journal of Bioequivalence \& Bioavailability aims to disseminate the results of such studies that most often either validate or negate the possibility of clinical implementation of pharmaceutical formulations. The importance of the journal lies in its direct implications in the clinical settings. Some of the most crucial articles published in the current issue of the journal are described in here.

Development of drugs that have bioavailability similar to the prevalent ones is essential to ensure that there are sufficient alternative treatment options. The importance of such drugs is especially realized under circumstances where there is acute shortage of the said drug or when a patient is found to be showing side effects against the said drug. Hence, scientists are constantly engaged identifying novel pharmaceutical candidates and then testing their efficacy against analogous pharmaceutical formulations. There are two possible outcomes of such studies; either the new drug may match up or exceed in bioavailability and therapeutic efficacy or it may lack the said functions. If the outcome is positive then it is highly likely that the new drug will be further tested and used in the formulation of substitute medicines. The article published by Dolores et al. presented a study that was intended to check the bioavailability of acetylsalicylic acid formulations (Ecasil- $81^{\circ}$, $81 \mathrm{mg}$ coated tablet) to be used as antithrombotic agents. The results indicated that the test formulation was equivalent with that of the reference formulation and may thus be further studied and applied in clinical settings [1].

A similar study on was performed on imatinib formulations and the results were reported by Vargas and Villarraga. The study encompasses comparative analysis of bioequivalence between Zeite ${ }^{\circ}$, Laboratorio Synthesis S.A.S., Colombia, and the conventionally applied reference formulation, Glivec ${ }^{\oplus}$, Novartis Pharma. The formulations were tested on 30 healthy Colombian volunteers and the plasma concentration of the active drug components was measured with the help of high performance liquid chromatography with ultraviolet detector, HPLC UV. Statistical analysis of multiple parameters viz. $C_{\max }, A U C_{\text {all }}$ and $\mathrm{AUC}_{0-\mathrm{Inf}}$ indicated that the test formulation has almost similar bioequivalence as that of the reference and can thus be administered inter-changeably [2].

Vargas and Villarraga published yet another bioequivalence study in the current issue of the journal. The article was specifically aimed to use the results obtained to showcase the importance of application of generic drugs. The said study was aimed to perform comparative pharmacokinetic analysis of two pharmaceutical formulations i.e. Oxicodal $^{\circ}$, Synthesis Laboratory S.A.S, Colombia and Trileptal ${ }^{\circ}$,
Novartis Laboratory. The experimental approach followed in this study was similar with that of the previous one and the results thus obtained also indicated bioequivalence [3].

The article published by Vemula et al. was specifically intended to highlight the advantages of application of effervescent floating mini-tablets of Ketorolac Tromethamine (KTM). In order to do so, the authors used bioequivalence studies to compare the physiological availability of the mini-tablets with that of the conventionally applied mini-tablets. The results obtained indicated that floating mini-tablets have dual advantages of decreasing the frequently reported irritant effects of administration of KTM and maintaining a comparatively lower dosage of the drug for prolonged periods so as to enhance its therapeutic efficacy. The results obtained from Pharmacokinetic studies of the formulation as tested on male albino rabbits indicated that minitablets had $2.25 \mathrm{X}$ bioavailability and $1.35 \mathrm{X}$ higher $\mathrm{C}_{\max }$ as compared to the already standardized immediate release core mini-tablet forms. The authors used the results obtained to propose that KTM effervescent compression-coated floating mini-tablets are the most preferable way of oral administration of the drug [4].

The increasing popularity of the notion of increased application of generic drugs has further intensified the need of conduct of bioequivalence studies. The results obtained from such studies can be used to either approve or reject the possible interchangeable application of generic drugs as opposed to the ones identified by brand names. The article published by Yerino et al. presented a similar study that was conducted to make comparative analysis of bioequivalence of a novel $12 \mathrm{mg}$ film-coated Perampanel formulation with that of a branded reference product. The drugs were administered in healthy subjects and plasma levels of the drug were determined after $168 \mathrm{~h}$. It was found that there were no significant differences between the bioequivalence of the test formulation and the reference product [5]. The study is yet another proof of viability of application of generic drugs.

However, one of the risk factors associated with the generic drugs is that they may contain non-specific active components or impurities or may even contain variable masses of the active drug. All these factors are known to impact the therapeutic efficacy of the formulation. Hence, it is highly recommended that though the concept of generic drugs should be propagated, it should also be verified whether these drugs have any of the above described discrepancies. The article published by Aljohani et al. conducted a similar study on Ciclosporin, a prevalently used immunosuppressant usually administered after organ transplantation

*Corresponding author: Edward T. Maggio, Aegis Therapeutics LLC, 11770 Bernardo Plaza Ct., Suite 353, San Diego, CA 92128, United States, Fax: (858) 618-1441; Tel: (858) 967-6840; E-mail: emaggio@aegisthera.com

Received September 23, 2017; Accepted September 25, 2017; Published September 29, 2017

Citation: Maggio ET (2017) Bioequivalence and Bioavailability. J Bioequiv Availab 9: e81. doi: 10.4172/jbb.10000e81

Copyright: () 2017 Maggio ET. This is an open-access article distributed under the terms of the Creative Commons Attribution License, which permits unrestricted use, distribution, and reproduction in any medium, provided the original author and source are credited. 
surgery. The authors used seven different ciclosporin formulations that were obtained from various countries of Columbia (C), Egypt (E), India (I), Jordan (J), Pakistan (P), Saudi Arabia (S), and Turkey (T). Analysis of the results obtained from dissolution test as well as other analytical procedures indicted that a few of the tested ciclosporin formulations contained an array of unidentified impurities. Furthermore, the relative mass of the active drug was also not as specified. These results were used to conclude that applicable of generic drugs cannot be generalized until and unless the various formulations are tested and verified [6].

The article published by Ali et al. described the prevalence, risk factors and prevalent challenges in diagnosis and treatment of Dengue fever in Pakistan. The authors presented a wholesome analysis of the origin, serotypes, characteristic diagnostic features as well as socioeconomic and chronic health implications of the disease. The authors also presented an elaborate account of the possible strategies that can be implemented to minimize the extent and severity of the disease on a population level [7].

Demonstration of bioequivalence among biotherapeutics poses unique and much more serious problems, in particular variable immunogenicity and different degrees of anaphylaxis arising in large part from differences in the chemical composition of the biotherapeutic. Variable oxidative damage is caused by reactive peroxides, epoxy acids, and aldehydes, which spontaneously arise and which are found in differing amounts in all lots of polysorbate 80 (Tween 80 ) and polysorbate 20 (Tween 20 ), along with varying amounts of unreacted starting materials. Polysorbates are also intrinsically anaphylactogenic. As a further complication, differences in the immunogenicity and anaphylaxis profiles of biotherapeutics may only become apparent once the product has been administered over an extended time to a sufficiently large enough group of patients. So while two biotherapeutics may be similar, differences in the protein API (e.g., amino acid sequence or glycosylation) and formulation components, particularly the polysorbates which are present in roughly $70 \%$ of all biotherapeutics, mean that they are not likely to be truly bioequivalent in the same sense as small molecule drugs.

\section{References}

1. Dolores RC, Antunes NJ, Moreno R, Di Vaio P, Magli E, et al. (2017) Comparative Bioavailability Study of Two $81 \mathrm{mg}$ Coated Tablet Formulations of Acetylsalicylic Acid in Fasting Healthy Volunteers. J Bioequiv Availab 9: 477483.

2. Vargas M, Villarraga E (2017) Bioequivalence Study of Imatinib Formulations that Contain 400 mg in Healthy Colombians. J Bioequiv Availab 9: 484-488.

3. Vargas M, Villarraga EA (2017) 600 mg Oxcarbazepine Tablets Bioequivalence Study. J Bioequiv Availab 9: 489-492.

4. Vemula SK, Venisetty RK, Veerareddy PR (2017) Formulation and Pharmacokinetics of Ketorolac Tromethamine Floating Compression Coated Mini- Tablets. J Bioequiv Availab 9: 493-498.

5. Yerino GA, Feleder EC, Otero AM, Diaz L, Sakson M, et al. (2017) Comparative Bioavailability of Two Oral Perampanel Formulations in Healthy Subjects: A Randomized, Open Label, Single-Dose, 2-Way Crossover Study. J Bioequiv Availab 9: 501-508.

6. Aljohani B, Alotaibi F, Ghazaly E, Jaber JA, Perrett D, et al. (2017) Development and Validation of A HPLC-UV Method for Dissolution Testing of Ciclosporin: Its Application to The Measurement of Brand and Generic Versions from Different Countries. J Bioequiv Availab 9: 509-515.

7. Ali H, Alvi A, Fatima S, Zafar F, Naveed S, et al. (2017) Dengue Fever in Pakistan, Episodes of Epidemic to Endemic: Treatment Challenges, Prevention and Current Facts. J Bioequiv Availab 9: 473-476. 